ISSN. 2775-4324 (Online)

Journal of Physical Activity and Sports

Volume 2, Nomor 3, Bulan 2021, 303-309

Journal of Physical Activity and Sports

\title{
Perbandingan Interval Training dan Circuit Training terhadap Peningkatan Daya Tahan Anaerobik SSB Putra Mororejo U-16
}

\author{
Rocky Alexander $\mathbf{R}^{1} *$, Muh. Isna Nurdin Wibisana ${ }^{2}$, Pandu Kresnapati ${ }^{3}$ \\ 1,2,3 Program Studi Pendidikan Jasmani Kesehatan dan Rekreasi, Fakultas Pendidikan Ilmu Pengetahuan Sosial \\ dan Keolahragaan, Universitas PGRI Semarang \\ * Coressponding Author. E-mail: alexramadhan031@gmail.com
}

\begin{abstract}
The purpose of this study was to determine the effect of interval training and circuit training on the anaerobic endurance of soccer players on the SSB Putra Mororejo U-16 team. The method in this research is an experimental research design with a Quasi Experiment Design with a pretest-posttest control group design. The instrument used to measure anaerobic endurance is the Running-based Anaerobic Sprint Test (RAST). The sample of this study was 20 players of SSB Putra Mororejo who were divided into two groups, namely the interval training group and the circuit training group. The results of the paired sample t-test concluded that there was an effect of treatment interval training and circuit training on anaerobic endurance. In the independent sample t test, interval training was more effective in increasing anaerobic endurance than circuit training. This is evidenced by the data obtained that the increase in interval training has a percentage increase of $40.96 \%$ and circuit training has an increased percentage of $24.96 \%$. Based on the results of the study, it can be concluded that interval training is more effective than circuit training in an effort to increase anaerobic endurance.
\end{abstract}

Keywords: interval training, circuit training, anaerobic endurance.

\begin{abstract}
Abstrak
Tujuan penelitian ini adalah untuk mengetahui pengaruh interval training dan circuit training terhadap daya tahan anaerobik pemain sepak bola pada tim SSB Putra Mororejo U-16. Metode dalam penelitian ini adalah eksperimen dengan desain penelitian Quasi Eksperimen Design dengan pretest-posttest control group design. Instrument yang digunakan untuk mengukur daya tahan anaerobik adalah Running-based Anaerobic Sprint Test (RAST). Sampel dari penelitian ini adalah 20 pemain SSB Putra Mororejo yang dibagi dalam dua kelompok yaitu kelompok interval training dan circuit training. Hasil uji paired sample t-test disimpulkan bahwa ada pengaruh treatment interval training dan circuit training terhadap daya tahan anaerobik. Pada uji independent sample t test, interval training lebih efektif dalam upaya peningkatan daya tahan anaerobik daripada circuit training. Hal itu dibuktikan dengan diperolehnya data peningkatan interval training memiliki presentase peningkatan sebesar 40,96\% dan circuit training memiliki peningkatan presentase sebesar 24,96\%. Berdasarkan hasil penelitian dapat disimpulkan bahwa interval training lebih efektif dibandingkan circuit training dalam upaya peningkatan daya tahan anaerobik.
\end{abstract}

Kata kunci: interval training, circuit training, daya tahan anaerobik.

\section{PENDAHULUAN}

Sepakbola adalah salah satu cabang olahraga yang paling digemari disegala lapisan masyarakat Indonesia. Sukatamsi (2003: 21) menyatakan bahwa sepakbola merupakan suatu permainan beregu yang dimainkan oleh dua regu maing-masing regunya terdiri dari sebelas orang pemain termasuk 
penjaga gawang, permainan bola dilakukan dengan seluruh bagian badan kecuali dengan tangan, pada dasarnya seluruh permainan dilakukan dengan ketrampilan kaki, dan hanya penjaga gawang yang boleh menggunakan seluruh anggota badannya untuk menjaga gawangnya agar lawan tidak memasukkan bola ke gawangnya.

Para pemain sepakbola membutuhkan unsur-unsur kemampuan fisik yang dapat memberikan pengaruh terhadap ketrampilan pemain sepakbola. Kualitas ketrampilan teknik dasar bermain setiap permainan tidak lepas dari faktor-faktor kondisi fisik, yaitu kecepatan, ketepatan, kekuatan, kelenturan, kelincahan, keseimbangan, daya tahan, koordinasi, dan reaksi (Jazi, 2014). Dalam kemampuan fisik permainan sepakbola dipengaruhi oleh kemampuan stamina atau daya tahan anaerobiknya pada seorang pemain. Daya tahan anaerobik adalah proses pemenuhan kebutuhan tenaga didalam tubuh untuk memanfaatkan glikogen agar menjadi sumber tenaga tanpa bantuan oksigen dari luar.

Akan tetapi banyak pemain sepakbola di SSB Putra Mororejo U-16 yang memiliki stamina atau daya tahan anaerobik yang kurang baik. Berdasarkan hasil wawancara dengan pelatih di SSB Putra Mororejo U-16, pemain memiliki tingkat kemampuan fisik yang masih kurang, hal ini diperoleh dari hasil uji coba bertanding yang dilakukan oleh SSB Putra Mororejo U-16. Dari hasil tersebut pemain masih kesulitan dalam melakukan pola bertahan maupun menyerang, sehingga pemain tidak bisa menampilkan permainan terbaiknya. Dengan kondisi yang dimiliki oleh pemain saat ini, maka diperlukan adanya latihan khusus untuk meningkatkan stamina dan daya tahan anaerobiknya.

Latihan yang memfokuskan pada stamina dan daya tahan anaerobik bisa berupa interval training dan circuit training. Latihan interval training dan latihan circuit training dapat dilakukan pada awal-awal musim atau jauh sebelum pertandingan, kompetisi ataupun kejuaraan dilaksanakan. Latihan interval training dan circuit training dapat dijadikan sebagai program latihan untuk meningkatkan komponen-komponen kondisi fisik antara lain daya tahan, kekuatan, reaksi, dan kecepatan dikarenakan memiliki persentase kenaikan yang kebih besar dari latihan interval training (Sugeng, 2018).

Latihan interval adalah latihan yang dilakukan dengan menentukan waktu capaian dengan selang waktu istirahat aktif yang telah ditentukan (Faisal, 2020). Sedangkan latihan circuit training merupakan suatu program latihan yang dikombinasikan dari beberapa latihan yang tujuannya dalam melakukan suatu latihan sirkuit akan tercakup latihan untuk kekuatan otot, ketahan otot, kelentukan, kelincahan, keseimbangan dan ketahanan jantung paru. Latihan sirkuit training ini merupakan latihan yang dapat meningkatkan komponen dalam kebugaran jasmani ( Mursain, 2018).

Berdasarkan latar belakang di atas, dapat diambil judul "Perbandingan Interval Training dengan Circuit Training terhadap Peningkatan Daya Tahan Anaerobik Pemain Sepakbola Tim SSB Putra Mororejo U-16". Tujuan dalam penelitian ini adalah untuk mengetahui pengaruh interval training dan circuit training terhadap daya tahan anaerobik pemain sepak bola pada tim SSB Putra Mororejo U-16 


\section{METODE}

\section{Metode dan desain}

Metode dalam penelitian ini adalah eksperimen. Desain eksperimen yang digunakan dalam penelitian ini adalah Quasi Eksperimen Design dengan pretest-posttest control group design. Desain ini mempunyai kelompok kontrol, tetapi tidak dapat berfungsi sepenuhnya mengontrol variabel-variabel luar yang mempengaruhi pelaksanaan experimen (Sugiyono, 2017: 114).

\section{Partisipan}

Populasi dari penelitian ini adalah seluruh tim SSB Putra Mororejo U-16. Sampel dari penelitian ini adalah 20 pemain SSB Putra Mororejo yang dibagi dalam dua kelompok yaitu kelompok interval training dan circuit training. Pengambilan sampel menggunakan Purposive Sampling.

\section{Instrumen}

Dalam penelitian ini instrumen yang digunakan untuk mengukur daya tahan anaerobik adalah Running-based Anaerobic Sprint Test (RAST). Tes ini mempunyai validitas $=0,897$ serta hasil uji reliabilitas $=0,919$.

\section{Prosedur}

Pelaksanaan tes sebagai berikut Sikap permulaaan peserta berdiri dibelakang garis start. Pada aba-aba "siap" peserta mengambil sikap start berdiri, siap untuk lari. Pada aba-aba "YA" dengan di bunyikannya peluit peserta lari secepat mungkin, menempuh jarak 35 meter, selama 6 repetisi, dan repetisi tiap satu repetisi istirahat 10 detik dan terus dilakukan sampai repetisi ke 6. Mencatat masingmasing waktu antar repetisi sejak aba-aba "YA" hingga bunyi "pluit" tanda waktu selesai yang didapat selama lari 6 repetisi, kemudian data di konversi melalui RAST Calculator untuk mengetahui indek kelelahan yang menunjukkan dari kemampuan kapasitas anaerobik.

\section{Analisis Data}

Analisis Data menggunakan uji prasyarat yang meliputi uji normalitas, uji homogenitas, dan uji hipotesis menggunakan uji t.

HASIL DAN PEMBAHASAN (Gunakan Microsoft Word template style: Heading 1)

Tabel 1. Hasil Uji Normalitas

\begin{tabular}{|c|c|c|c|}
\hline \multicolumn{2}{|c|}{ Latihan } & Signifikansi & Keterangan \\
\hline Pretest & Circuit & 0,462 & Normal \\
\cline { 2 - 4 } & Interval & 0,109 & Normal \\
\hline Posttest & Circuit & 0,633 & Normal \\
\cline { 2 - 4 } & Interval & 0,136 & Normal \\
\hline
\end{tabular}


Dengan menggunakan SPSS, pada data pretest diperoleh Sig. circuit training 0,462 dan Sig. interval training 0,109. Pada data posttest diperoleh Sig. circuit training 0,633 dan Sig. interval training 0,136. Karena signifikansi data pretes maupun posttes pada circuit training dan interval training lebih dari 0,05 maka $\mathrm{H}_{0}$ diterima. Dapat disimpulkan bahwa sampel pada kelompok circuit training dan interval training berasal dari populasi yang berdistribusi normal.

Tabel 2. Hasil Uji Homogenitas

\begin{tabular}{|c|c|c|c|}
\hline Data & $\begin{array}{c}\text { Levene } \\
\text { Statistic }\end{array}$ & Sig. & Keterangan \\
\hline Pretest & 3,103 & 0,095 & Homogen \\
\hline
\end{tabular}

Dengan menggunakan SPSS diperoleh signifikansi data pretest 0,096 dan data posttest 0,966. Karena signifikansi data pretes maupun posttest lebih dari 0,05 maka $\mathrm{H}_{0}$ diterima. Dapat disimpulkan bahwa data pretest dan posttes kedua kelompok latihan memiliki varian data yang sama (homogen).

Tabel 3. Hasil Uji Paired Sample Test Interval Training

\begin{tabular}{|c|c|c|c|}
\hline & $\mathrm{t}$ & $\mathrm{Df}$ & Sig. (2-tailed) \\
\hline $\begin{array}{c}\text { Pretest- } \\
\text { posttest }\end{array}$ & 4,288 & 9 & 0,002 \\
\hline
\end{tabular}

Dengan menggunakan SPSS diperoleh nilai signifikansi 0,002. Karena 0,002 $<0,05$ maka $\mathrm{H}_{0}$ ditolak. Sehingga dapat dikatakan terdapat perbedaan rata-rata hasil pretest dan posttest pada interval training. Dapat disimpulkan bahwa terdapat pengaruh interval training terhadap daya tahan anaerobik pemain SSB Putra Mororejo U-16.

Tabel 4. Uji Paired Sample Test Circuit Training

\begin{tabular}{|c|c|c|c|}
\hline & $\mathrm{t}$ & $\mathrm{Df}$ & Sig. (2-tailed) \\
\hline $\begin{array}{c}\text { Pretest- } \\
\text { posttest }\end{array}$ & 4,671 & 9 & 0,001 \\
\hline
\end{tabular}

Dengan menggunakan SPSS diperoleh nilai signifikansi 0,001. Karena 0,001 $<0,05$ maka $\mathrm{H}_{0}$ ditolak. Sehingga dapat dikatakan terdapat perbedaan rata-rata hasil pretest dan posttest pada circuit training. Dapat disimpulkan bahwa terdapat pengaruh circuit training terhadap daya tahan anaerobik pemain SSB Putra Mororejo U-16.

Tabel 5. Uji Independent Sample Test

\begin{tabular}{|c|c|c|c|}
\hline & $\mathrm{T}$ & $\mathrm{df}$ & $\begin{array}{c}\text { Sig. (2- } \\
\text { tailed) }\end{array}$ \\
\hline $\begin{array}{c}\text { Posttest antar } \\
\text { kelompok }\end{array}$ & 0,942 & 8 & 0,359 \\
\hline
\end{tabular}


Dengan menggunakan SPSS diperoleh nilai signifikansi 0,359. Karena 0,359>0,05 maka $\mathrm{H}_{0}$ diterima. Sehingga tidak terdapat perbedaan rata-rata posttest interval training dan circuit training terhadap daya tahan anaerobik. Dapat disimpulkan bahwa pemberian treatmen interval training dan circuit training memberikan pengaruh yang sama dalam meningkatkan daya tahan anaerobik pemain SSB Putra Mororejo U-16.

Tabel 6. Peningkatan Daya Tahan Anaerobik

\begin{tabular}{|l|c|c|c|}
\hline Variabel & $\begin{array}{c}\text { Rata- } \\
\text { rata }\end{array}$ & Persentase & $\begin{array}{c}\text { Peningka } \\
\text { tan }\end{array}$ \\
\hline $\begin{array}{l}\text { Pretest } \\
\text { interval } \\
\text { training }\end{array}$ & 17,26 & $70,48 \%$ & \\
\hline $\begin{array}{l}\text { Posttest } \\
\text { interval } \\
\text { training }\end{array}$ & 7,23 & $29,52 \%$ & \\
\cline { 1 - 2 } $\begin{array}{l}\text { Pretest } \\
\text { circuit } \\
\text { training }\end{array}$ & 14,32 & $62,97 \%$ & \\
\cline { 1 - 2 } $\begin{array}{l}\text { Posttest } \\
\text { circuit } \\
\text { training }\end{array}$ & 8,42 & $37,03 \%$ & $25,94 \%$ \\
\hline
\end{tabular}

Peningkatan daya tahan anaerobik pemain SSB Putra Mororejo pada interval training sebesar 40,96\% dan pada circuit training sebesar 25,94\%. Karena peningkatan pada interval training dan circuit training terdapat perbedaan maka dapat disimpulkan bahwa daya tahan anaerobik dengan interval training lebih baik dibandingkan dengan daya tahan anaerobik menggunakan circuit training.

\section{PEMBAHASAN}

Berdasarkan hasil penelitian untuk mengetahui pengaruh atau tidak pemberian interval training dan circuit training terhadap peningkatan daya tahan anaerobik SSB Putra Mororejo dengan Paired Sample T-test diperoleh hasil bahwa ada perbedaan antara hasil sebelum dan sesudah diberikan interval training dan circuit training. Sehingga latihan tersebut berpengaruh terhadap daya tahan anaerobik pemain SSB Putra Mororejo.

Permainan Sepak bola memiliki waktu normal 90 menit. Dalam sepak bola terdapat dua faktor yang mempengaruhi daya tahan yaitu aerobik dan anaerobik. Daya tahan aerobik merupakan proses pemenuhan kebutuhan energi yang memerlukan bantuan oksigen. Untuk mengukur daya tahan aerobik dapat dilakukan dengan tes Multi Fitness Test (MFT). Sedangkan daya tahan anaerobik merupakan proses pemenuhan kebutuhan energi yang tidak memerlukan bantuan oksigen. Untuk mengukur daya tahan anaerobik dapat dilakukan dengan tes Running-based Anaerobic Sprint Test (RAST). Dalam sepak bola daya tahan anaerobik sangat diperlukan. Hal ini dikarenakan pada saat pergerakan pemain 
yang mendapatkan penguasaan bola atau tidak pasti ada pergerakan berlari atau menggiring bola tidak menggunakan oksigen.

Dalam penelitian ini untuk mengukur daya tahan anaerobik dilakukan dengan test RAST. Tes RAST yang digunakan terdapat 6 kali lari sprint. Setiap lari sprint terdapat beberapa pengaruh atau fase setiap lari. Fase yang pertama yaitu penyesuaian. Fase yang kedua dan ketiga yaitu atlet melakukan dengan cepat karena memiliki sumber energi karbohidrat. Fase kelima dan keenam yaitu atlet sudah merasakan kelelahan karena kehabisan sumber energi. Test RAST interval training pada pretest terdapat 7 pemain berkategori lelah dan 3 pemain berkategori tidak lelah. Sedangkan pada posttest terdapat 1 pemain berkategori lelah dan 9 pemain berkategori tidak lelah. Test RAST circuit training pada pretest terdapat 9 pemain berkategori Lelah dan 1 pemain berkategori tidak lelah. Sedangkan pada posttest terdapat 4 pemain berkategori lelah dan 6 pemain berkategori tidak lelah.

Dalam penelitian yang dilakukan di SSB Putra Mororejo diperoleh hasil pada penggunaan interval training sebesar 40,96\% dan pada circuit training sebesar 25,94\%. Hasil tersebut dikatakan baik tetapi belum maksimal. Perbedaan peningkatan daya tahan anaerobik antara interval training dan circuit training sebesar $15,02 \%$. Dalam penelitian ini pemberian interval training lebih baik dibandingkan dengan circuit training terhadap peningkatan daya tahan anaerobik pada SSB Putra Mororejo.

Dalam teori penelitian yang dilakukan oleh Mohammad Fadhil Ulum (2013), juga diperoleh hasil pengaruh dari interval pendek terhadap peningkaan daya tahan anaerobik pada pemain hoki diperoleh $\mathrm{t}$ hitung 2,328 > 2,201 $\mathrm{t}$ tabel, maka $\mathrm{H}_{0}$ ditolak yang berarti terdapat perbedaan rata-rata indeks kelelahan sebelum dan sesudah diberi perlakuan latihan interval. Hal ini berarti latihan interval dapat meningkatkan daya tahan anaerobik pada pemain hoki.

Studi lain juga dilakukan oleh Fandi Ari Wijaya (2018), diperoleh hasil pengaruh latihan interval pendek terhadap daya tahan anaerobik pada pemain akademi arema u-14 diperoleh hasil uji anova yang signifikan, maka dapat disimpulkan bahwa pemberian perlakuan latihan interval pendek terhadap peningkatan daya tahan anaerobik pada pemain Akademi Arema U-14.

\section{KESIMPULAN}

Berdasarkan hasil analisis terhadap data penelitian dapat disimpulkan sebagai berikut: 1) Terdapat pengaruh interval training terhadap daya tahan anaerobik pemain sepak bola tim SSB Putra Mororejo U-16 sebesar 29,52\%. 2) Terdapat pengaruh circuit training terhadap daya tahan anaerobik pemain sepak bola tim SSB Putra Mororejo U-16 sebesar 37,03\%. 3) Terdapat perbedaan antara daya tahan anaerobik pemain sepak bola yang diberikan interval training dengan circuit training pada tim SSB Putra Mororejo U-16 interval training sebesar 40,96\% dan circuit training sebesar 25,94\%.

\section{DAFTAR PUSTAKA}

Arikunto, S. (2013). Prosedur Penelitian. Jakarta: Rineka Cipta. 
Harsono. (2015). Periodisasi Program Pelatihan. Bandung: Remaja Rosdakarya.

Hasyim, I. (2018). Pengaruh metode latihan sirkuit terhadap kemapuan smash pada permainan bukutangkis.

Hidayat, S. (2014). Pelatihan Olahraga., Teori dan Metodologi. Yogyakarta: Graha Ilmu.

Jordy Faisal, E. S. (2020). Pengaruh Latihan Interval Training terhadap Daya Tahan Anaerobik Pemain Futsal Klub Putri Kabupaen Siak. STAMINA, 3(2), 112-123.

Kusumawati. (2015). Penelitian Pendidikan Penjasorkes. Bandung: Alfabeta.

Muh. Akmal Almy, S. (2014). Perbedaan Pengaruh Circuit Training dan Fartlek Training terhadap Peningkatan VO2MAX dan Indeks Massa Tubuh. Jurnal Keolahragaan, 2(3), 59-68.

Mursain, F. (2018). Pengaruh Latihan Circuit Training dan Interval Training terhadap Peningkatan VO2 MAX pada Pemain Futsal.

Sugiyono. (2017). Metode Penelitian Pendidikan. Bandung: Alfabeta.

Ulum, M. F. (2014). Pengaruh Latihan Interval Pendek terhadap Peningkatan Daya Tahan Anaerobik pada Pemain Hoki SMA Negeri 16 Surabaya Universitas Negeri Surabaya. Kesehatan Olahraga, 2(1), 1-10.

Widiyanto, M. Y. A. dan. (2014). Kemampuan Daya Tahan Anaerobik dan Daya Tahan Aerobik Pemain Hoki Putra Universitas Negeri Yogyakarta. Medikora, XII(1).

Wijaya, F. A. (2018). Pengaruh Latihan Inerval Pendek terhadap Daya Tahan Anaerobik pada Pemain Akademi Arema U-14 